\title{
Multiphysics Analysis of Ice-Polyurethane Adhesion under Flexural Loading using FEM Analysis
}

\author{
H Eidesen', Z Andleeb², H Khawaja1*, M Moatamedi ${ }^{3,4}$ \\ 1. UiT-The Arctic University of Norway \\ 2. Abyss Solutions, Pakistan \\ 3. Al Ghurair University, UAE \\ 4. Oslo Metropolitan University, Norway
}

\begin{abstract}
This paper present the Finite Element Analysis (FEA) Multiphysics technique, applied to study the strength of ice adhesion between the surface of polyurethane and ice. The theoretical study of this work is based on the Euler-Bernoulli beam theory that is used to solve a four-point bending problem to give the correlation of displacements with load and longitudinal stresses. The physical samples were prepared by freezing ice over the polyurethane surface and were tested experimentally in a four-point flexural setup. In the experiment, masses were added on the four-point bench until the ice separates from the surface. The results revealed that the ice adhesion on the surface of polyurethane is in the same range as with other polymers. The displacement at the time of separation was recorded, and the same conditions were used to perform numerical simulations in ANSYS ${ }^{\circledR}$ Workbench. The meshed ice-polyurethane Finite Element Method (FEM) model was tested for sensitivity. A good agreement was found between theoretical, experimental and numerical simulation results.
\end{abstract}

\section{INTRODUCTION}

The icing phenomenon is referred to when water droplets are cooled below the freezing temperature $\left(0^{\circ} \mathrm{C}\right)$ and freeze upon impact with a structure [1]. Ice exists in several different crystal structures, as well as two amorphous states [2]. The ordinary ice we find in our freezer is a hexagonal crystal structure called ice $-1 \mathrm{~h}$, where the numbers refer to individual water molecules [3]. The physical properties and the appearance of accreted ice vary widely [4-6]. It is known from published work that Young's modulus of ice varies between 4 GPa to 9 GPa [7-9]. In addition, it has also been reported that the value of Young's modulus for ice is related to temperature, grain size, density, and sample volume. Icing causes many serious problems; for example, icing causes aircraft and road accidents [10-14], the icing on ship hulls creates navigational difficulties [9], and the icing on wind turbines has many negative consequences $[15,16]$. These challenges are associated with the ice adhesive behavior [16]. There is no direct correlation to calculate the ice adhesion force [17]. However, researchers have given a number of theories [18,19]. The theories divide the force of Adhesion into four categories: electrostatic Adhesion [20,21], diffusive Adhesion [22,23], mechanical Adhesion, and chemical adhesion [24].

Corresponding Author: hassan.a.khawaja@uit.no 
The most common reason for ice adhesion is mechanical. The ice adheres when water seeps into the microscopic pores of the material substrate and freezes, thereby forming an interlocking mechanism [25]. Therefore, surface roughness has a significant effect on ice adhesion. For example, in general, ice adhesion on the surface of unpolished stainless steel is up to $1.65 \mathrm{MPa}$, while the ice adhesion on polished stainless steel is only $0.07 \mathrm{MPa}$ [17]. In the given study, ice is frozen over a polyurethane surface. Polyurethane is a polymer-based structure, and its mechanical properties may vary based on the curing process [26]. In addition, additives can be added to obtain a range of mechanical properties [27].

\section{MATERIAL}

This study uses the polyurethane tested and developed by the China Institute of Water Resources \& Hydropower Research Beijing IWHR-KHL Co. Ltd [28]. The product name is SK One Component Polyurethane. However, the polyurethane name will be used in the following sections of this paper. The company provided two distinct types of polyurethane for testing, namely anti-seepage polyurethane, and anti-abrasion polyurethane. Anti-seepage polyurethane is suggested as a sealant in either chemical tanks, as it has good resistance to chemical corrosion [29], or in dams to prevent water leaks through the concrete. Anti-abrasion polyurethane can be used in locations where high corrosion is expected. Locations of such can be water ducts from dams, on ships, due to the force of water while the ship is in transit, and so forth. Both variants of polyurethane are used in this study.

\section{EXPERIMENTAL SETUP}

The aim of this experiment is to generate observations of ice separation on a laboratory scale since bending induces longitudinal and shear stresses. Samples were prepared by freezing ice from tap water over the polyurethane surfaces, as explained in section 4 . To obtain the necessary data to estimate the ice adhesion, a four-point bench was used. A four-point bench has two loading points and two support points. A CAD model image of the bench that was used to obtain the results in this paper is shown in Fig. 1. In Fig. 1, (a) is the side view, and (b) is the top-view. The parameters of the four-point test bench are shown in Table. 1 below.

Table 1: Parameters of the four-point test bench and the polyurethane specimen

Description Variable $=$ Value (unit)
Length of specimen, $l=260 \mathrm{~mm}$
Width of specimen, $b=60 \mathrm{~mm}$
Thickness of specimen, $t_{s}=90 \mathrm{~mm}$
Thickness of ice, $t_{i}=0.9-1.0 \mathrm{~mm}$
Distance between the loads points $L_{2}=160 \mathrm{~mm}$
Distance between support points $L=200 \mathrm{~mm}$




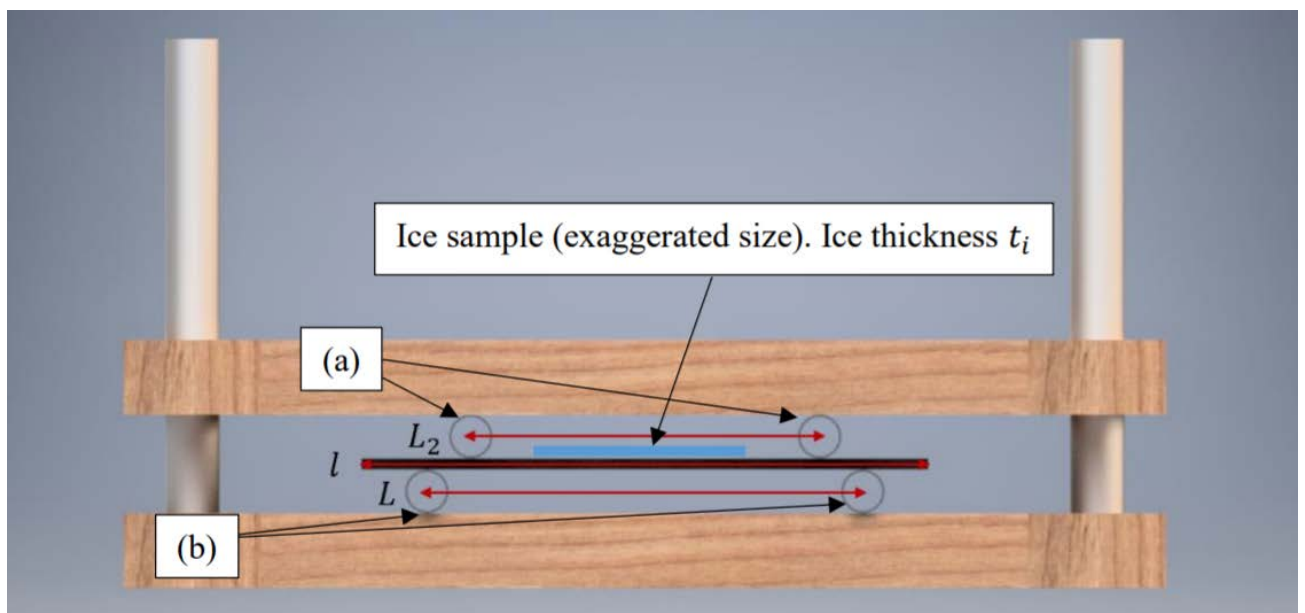

(a) Side View

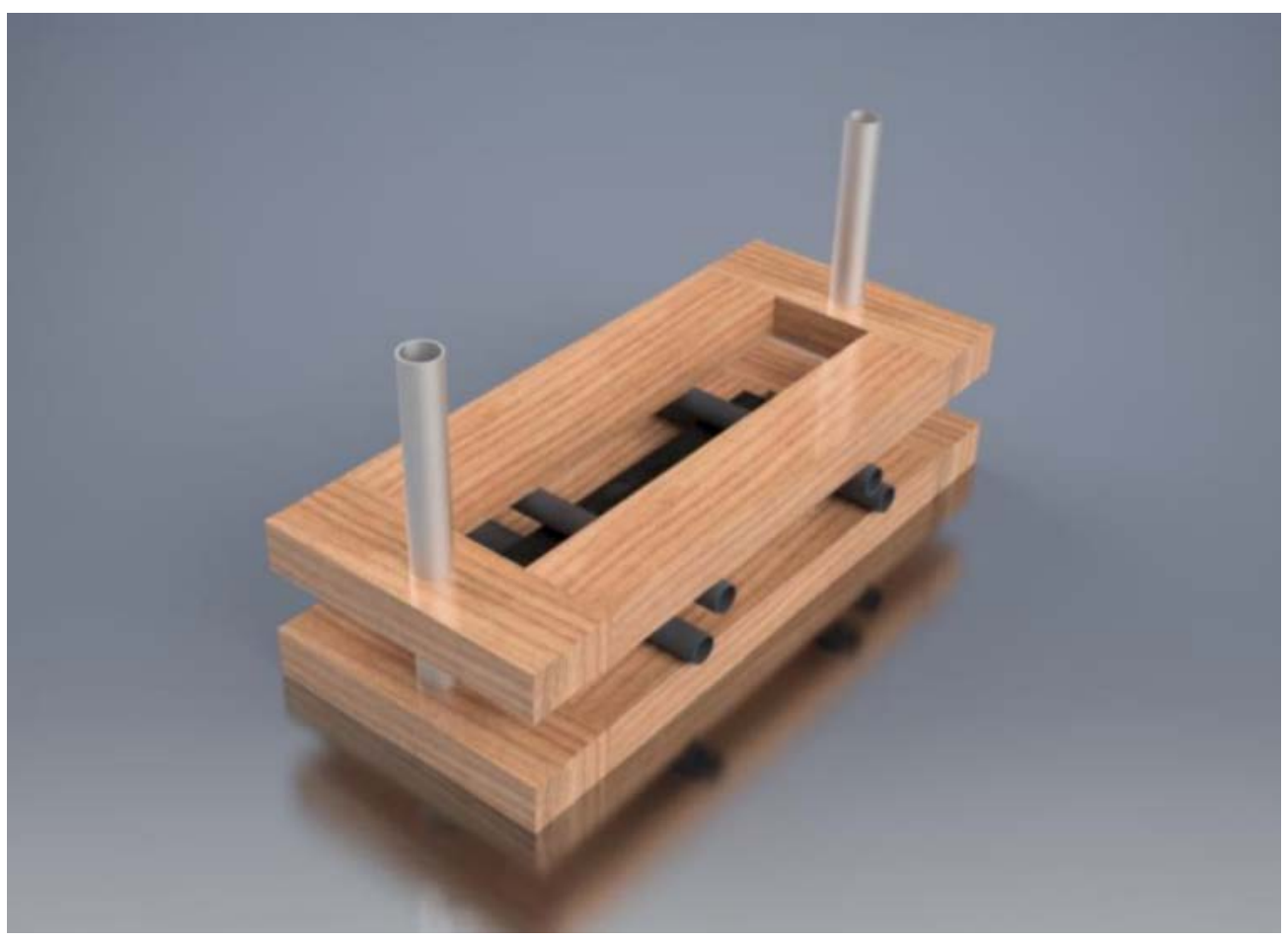

(b) Top View

Figure 1: Four-point test bench. The polyurethane specimen is placed in the middle. Modelled in Autodesk Inventor Professional 2017. 


\section{PREPARATION OF SAMPLES}

The polyurethane samples were cut in appropriate sizes $(260 \mathrm{~mm} \times 60 \mathrm{~mm})$. Both the sample and the four-point bench were put in the freezer $\left(-25^{\circ} \mathrm{C}\right)$ overnight to ensure an even temperature in the entire specimen. In the design of the test bench, there were two support rods. These were added to the system to ensure that the load joints only moved downwards when the load was applied, and hence, ensure more accurate results.

The entire apparatus and both anti-abrasion and anti-seepage polyurethane samples were put inside the cold room overnight. When the objects were properly cold, masses were added on the four-point bench while still inside the cold room. When the preparation for ice adhesion, liquid water was poured on the surface of the polyurethane. This was done while the polyurethane specimens were inside the freezer to minimize errors due to moving the specimen to the freezer from the ambient room. Consequently, a decent slab of ice was obtained on top of the polyurethane samples. After approximately 6 hours, the liquid water had turned to solid ice. See Fig. 2 of the ice on the specimen on polyurethane. This specimen has been placed on the four-point test bench.

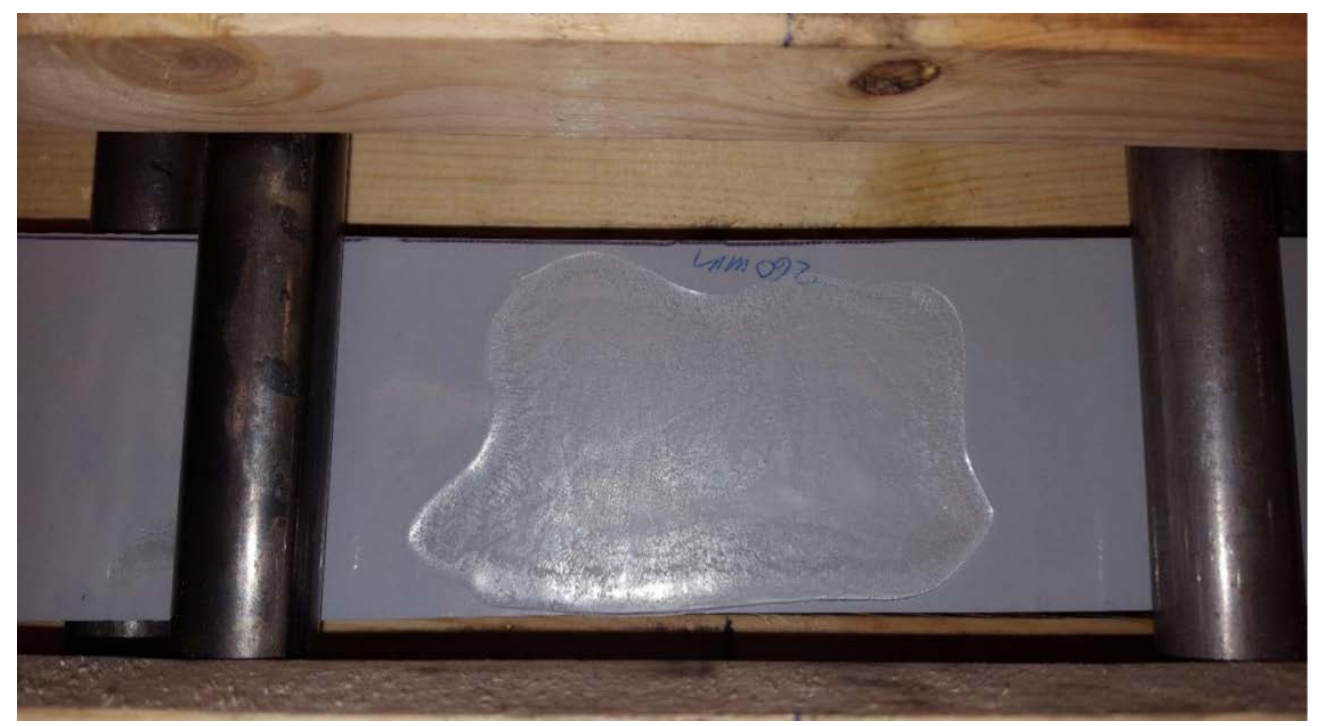

Figure 2: ice on polyurethane

\section{DATA GATHERING}

The load and deflection data were gathered while both the apparatus and the specimen were still inside the cold room. The initial load from the loading frame was $1.25 \mathrm{~kg}$. The added mass came from iron weights, and the added mass had an increment of $1.25 \mathrm{~kg}$ each time. The initial displacement was recorded before the first $1.25 \mathrm{~kg}$ iron weight was added in the middle of the upper frame. At each time more weight was added, the new displacement was recorded, as shown in Fig. 3.

When the ice had separated from the surface, the experiment was concluded. At each time more weight was added, the ice was gently poked on the side to check if for ice adhesion. 


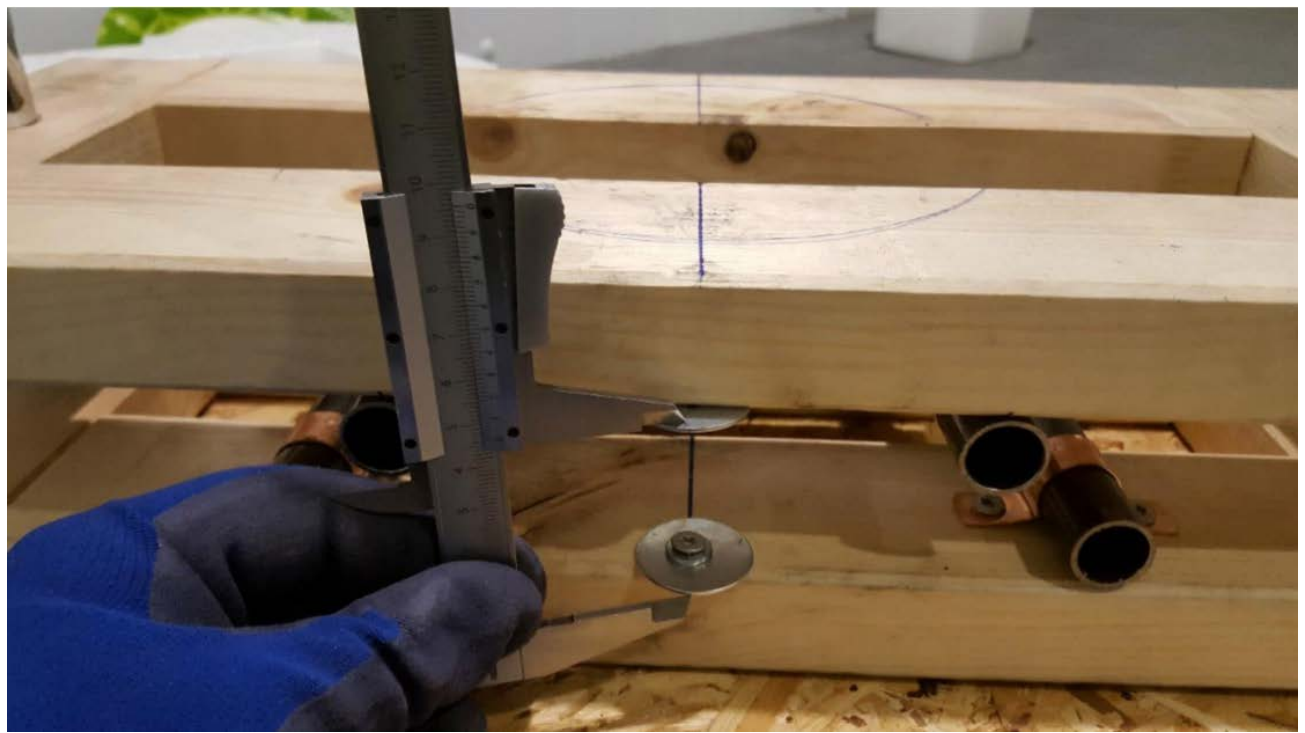

Figure 3: Recording displacement using a Vernier caliper. At this instant, the only load is from the upper frame alone. The middle of the frame is marked with a circle.

\subsection{Conditions of Experimental Location}

The experiments were performed inside the cold room $\left(-30^{\circ} \mathrm{C}\right)$ in order to avoid building any cracks in the sample due to thermal shock. Thermal shock may introduce cracks in the ice samples and hence lead to errors in results [26].

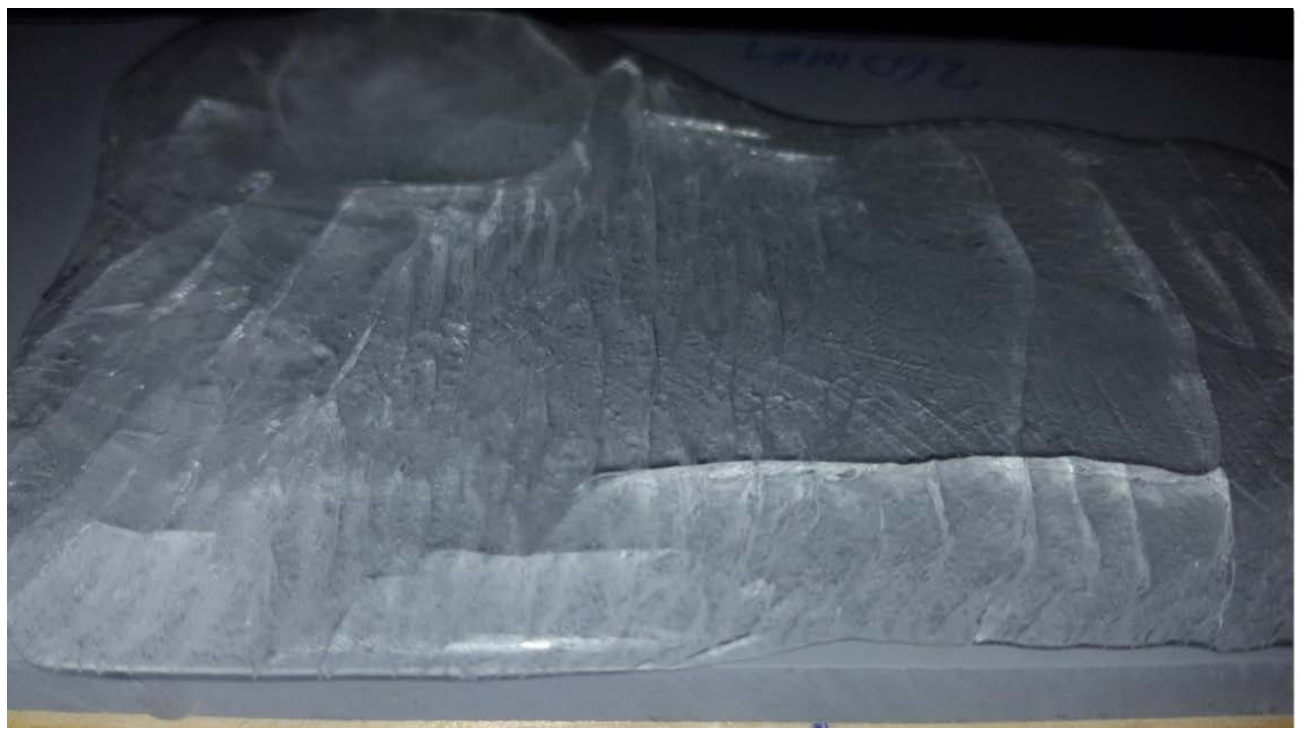

Figure 4: Ice has broken down due to shear stress, and there are no forces restraining the ice to the polyurethane. 
The displacement when the ice adhesion seized to exist was measured, the experiment was concluded. The identical experiment was done multiple times to ensure that substantial amounts of data were gathered. For each time water was poured, the ice had different areas, which was expected. However, all areas were recorded prior to starting the experiment. When the masses were added on the four-point bench, the deflection at point $L_{1}$ was recorded using a vernier caliper. This was done after each time when the added load was increased on the bench. Additionally, after each time when the load had increased, the ice was gently poked on the side to see if ice adhesion was still present. Fig. 4 shows when the ice has broken due to shear stresses, and there are no forces restraining the ice to the polyurethane.

\section{ANALYTICAL STUDY IN MATLAB®}

The Euler-Bernoulli beam theory [30-32] was used to calculate the maximum deflection in the center of the four-point bending specimen in MATLAB ${ }^{\circledR}$ software [33]. Maximum deflection $\delta_{\max }$ is given in Equation (1):

$$
\delta_{\text {max }}=\delta_{\text {center }} \quad=\frac{P L_{1}}{48 \mathrm{EI}_{\mathrm{t}}}\left(3 L^{2}-4 L_{1}^{2}\right)
$$

where $\delta_{\text {center }}$ is the deflection in the centre, $L$ is the total length, $L_{1}$ is the distance between the support point to the loading point, $E$ is Young's modulus, and $I$ is the total moment of Inertia about the neutral axis.

This specimen contains ice and polyurethane, two kinds of different materials, and therefore the rule of mixtures is introduced to find the material properties of the sample. It is valid to assume that under tensile loading, the Young's moduli of the sample can be described as given in Equation (2):

$$
E=E \frac{A_{\text {ice }}}{A}+E_{p} \frac{A_{p}}{A}
$$

where $E, E_{i c e}$ and $E_{p}$ are Young's moduli of the sample, ice, and polyurethane, respectively. $A, A_{i c e}$ and $A_{p}$ are cross-sectional areas of the sample, ice, and polyurethane, respectively.

Stress calculations in beams are performed with respect to the neutral axis. The neutral axis of a beam goes through the centroid of its cross-section. Since there are two materials that have different Young's moduli $E_{i c e}$ and $E_{p}$, it is safe to assume that $E_{i c e}>E p$, the expansion factor, also known as balance coefficient $(n)$, is given in Equation (3):

$$
n=\frac{E p}{E_{\text {ice }}}
$$

In order to have a similar inertial effect of both materials, the balance coefficient is multiplied by the width of polyurethane to create a hypothetical area. The neutral axis of the sample shifts because of the difference in the Young's moduli of ice and polyurethane; similarly, the values of the moment of area and the moment of Inertia also change. These values are required to be calculated with respect to the new neutral axis (Equation (3)). The total moment of area $Q_{t}$ and Inertia $I_{t}$ are given in Equations (4) and (5): 


$$
\begin{gathered}
Q_{t}=Q_{i c e}+Q_{p} \\
I_{t}=I_{i c e}+I_{p}
\end{gathered}
$$

where $Q_{i c e}$ is the area moment of ice, $Q_{p}$ is the area moment of polyurethane, $I_{i c e}$ is the moment of Inertia of ice and $I_{p}$ is the moment of Inertia of polyurethane. $Q_{i c e}, Q_{p}, I_{i c e}$ and $I_{p}$ are given in Equations (6) to (9):

$$
\begin{gathered}
Q_{i c e}=t_{i c e} \cdot b \cdot\left(y_{i c e}-Y\right) \\
Q_{p}=t_{p} \cdot n \cdot b \cdot\left(y_{p}-Y\right) \\
I_{i c e}=\frac{b \cdot t_{p}^{3}}{12}+n \cdot b \cdot t_{p} \cdot\left(y_{p}-Y\right) \\
I_{p}=\frac{n \cdot b \cdot t_{p}^{3}}{12}+n \cdot b \cdot t_{p} \cdot\left(y_{p}-Y\right)
\end{gathered}
$$

where $y_{i c e}$ and $y_{p}$ are distances of the neutral axis of ice and polyurethane from the reference axis respectively.

The longitudinal stresses in the ice and polyurethane are given in Equations (10) and (11):

$$
\begin{gathered}
\sigma=-\frac{M(y-Y)}{I_{t}},\left(t_{p} \leq y \geq t_{p}+t_{i c e}\right) \\
\sigma_{x, p}=-\frac{n M(y-Y)}{I_{t}},\left(0 \leq y \geq t_{p}\right)
\end{gathered}
$$

where $\sigma_{x}$,ice and $\sigma_{x, p}$ are the longitudinal stresses in ice and polyurethane, respectively. $y$ is the position based on the reference axis (placed at the bottom of the sample).

Similarly, shear stresses in the ice and polyurethane are given in Equations (12) and (13):

$$
\begin{gathered}
\tau_{x, i c e}=\frac{V Q_{i c e}}{I_{t} b},\left(y=t_{p}\right) \\
\tau_{x, p}=\frac{n V Q_{p}}{I_{t} b},\left(y=t_{p}\right)
\end{gathered}
$$

where $\tau_{x, i c e}$ and $\tau_{x, p}$ are the shear stresses at the interface of ice and polyurethane, respectively. 


\section{ICE ADHESION IN ANSYS $₫$}

In ANSYS ${ }^{\circledR}$ [34], a setup of the four-point test was modeled, as shown in Fig. 5 below.

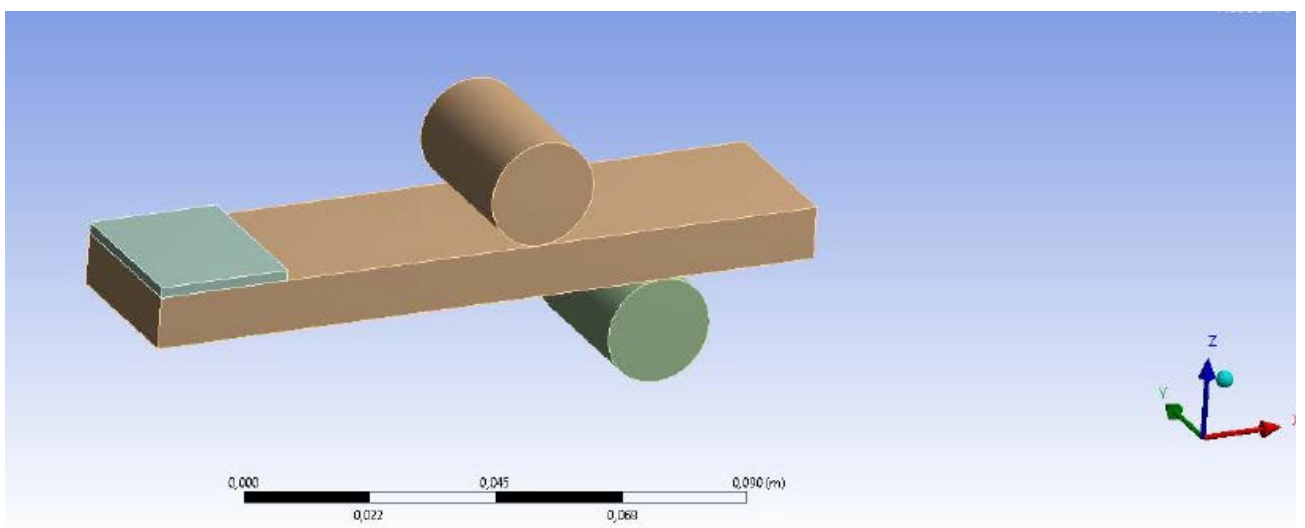

Figure 5: Ice adhesion test in ANSYS ${ }$. The light-colored blue box on the left side represents the ice.

This model represents $1 / 4$ of the complete system. The reason why only a quarter of the complete system was modeled is to minimize the computational load when solving the model. Inside the software, symmetry regions were put on the sides so that the final model was appropriate, according to Fig. 1 and 2. In Fig. 6 below, symmetry and the mesh have been added. The light-shaded block between the load points represents the ice. For each run, the area of the ice was modeled according to table 2 and 3 in section 8.

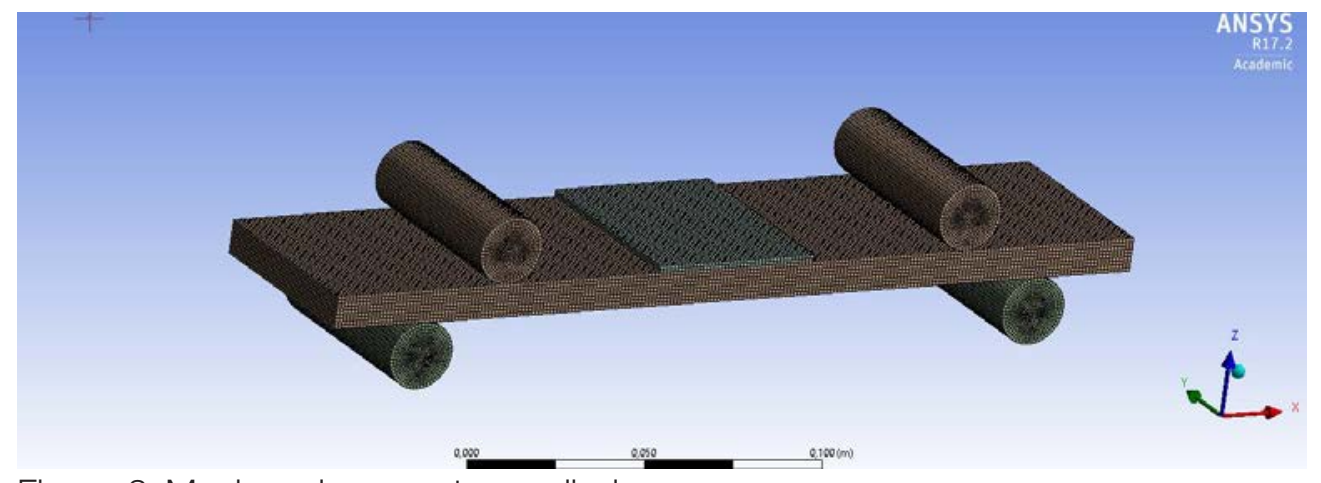

Figure 6: Mesh and symmetry applied.

In Fig.6, the mesh and symmetry have been applied to the system. In the setup, prior to running the simulation in the ANSYS ${ }^{\circledR}$-software, the maximum displacement, in the $\mathrm{z}$ direction, was set according to the displacement at the point ice separated from the polyurethane surface in the experiments. The recorded longitudinal stress from the simulation was recorded in the middle of the system. In ANSYS ${ }^{\circ}$, displacement in z-direction was applied, according to the experimental results. 
The ice in the ANSYS ${ }^{\circledR}$ model was not modeled according to the real ice shape of the ice. The area of the ice was estimated using basic math and trigonometry. Trigonometry was applied if the frozen ice had triangles at some point on the surface. Based on these results, it was possible to approximate the area of ice on the surface of polyurethane.

\section{RESULTS AND DISCUSSION}

The results are given in two sections; experimental, analytical, and numerical simulation results. Theoretical results are obtained by solving Euler-Bernoulli beam theory for four-point bending in MATLAB ${ }^{\circledR}$. Experimental results were achieved via strain gauge in a four-point bending test. Numerical results were from linear static analysis in ANSYS ${ }^{\circledR}$ Multiphysics software.

\subsection{Experimental Results}

The replication of the mechanical behavior of ice under flexural loading and the delamination of ice from the surface of polyurethane were the two key points to be noted. The experiments were repeated with both anti-seepage and anti-abrasion polyurethane. The displacements with loads for each sample are given in Tables 2 and 3.

\subsubsection{Anti-seepage polyurethane}

The data obtained using Vernier caliper to obtain the displacement and the added mass from experiments on anti-seepage polyurethane are shown below.

Table 2: Data from experiments with ice adhesion on anti-seepage polyurethane

\begin{tabular}{|c|c|c|c|}
\hline \multicolumn{2}{|c|}{ Experiment: $1\left(\right.$ area $\left.\mathrm{A}=52.7 \mathrm{~cm}^{2}\right)$} & \multicolumn{2}{|c|}{ Experiment: $2\left(\right.$ area $\left.\mathrm{A}=51.4 \mathrm{~cm}^{2}\right)$} \\
\hline Mass (kg) & Displacement (mm) & Mass (kg) & Displacement (mm) \\
\hline 1.25 & 1.28 & 1.25 & 1.13 \\
\hline 2.50 & 1.52 & 2.50 & 1.74 \\
\hline 3.75 & 1.95 & 3.75 & 2.85 \\
\hline 5.00 & 2.12 & 5.00 & 3.21 \\
\hline 6.25 & 2.57 & 6.25 & 3.30 \\
\hline 7.50 & 3.07 & 7.50 & 3.95 \\
\hline \multicolumn{2}{|c|}{ Experiment: $3\left(\right.$ area $\left.\mathrm{A}=58.4 \mathrm{~cm}^{2}\right)$} & \multicolumn{2}{|c|}{ Experiment: $4\left(\right.$ area $\left.\mathrm{A}=59.5 \mathrm{~cm}^{2}\right)$} \\
\hline 1.25 & 1.27 & 1.25 & 1.42 \\
\hline 2.50 & 1.45 & 2.50 & 2.15 \\
\hline 3.75 & 1.61 & 3.75 & 2.52 \\
\hline 5.00 & 2.71 & 5.00 & 3.03 \\
\hline 6.25 & 3.12 & 6.25 & 3.38 \\
\hline 7.50 & - & 7.50 & 4.01 \\
\hline \multicolumn{2}{|c|}{ Experiment: 6 (area $\left.A=51.8 \mathrm{~cm}^{2}\right)$} & \multicolumn{2}{|c|}{ Experiment: $7\left(\right.$ area $\left.\mathrm{A}=52.9 \mathrm{~cm}^{2}\right)$} \\
\hline 1.25 & 1.28 & 1.25 & 1.17 \\
\hline 2.50 & 1.45 & 2.50 & 1.55 \\
\hline 3.75 & 2.32 & 3.75 & 2.62 \\
\hline 5.00 & 2.84 & 5.00 & 2.93 \\
\hline 6.25 & 3.41 & 6.25 & - \\
\hline 7.50 & 3.73 & 7.50 & - \\
\hline
\end{tabular}




\subsubsection{Anti-abrasion Polyurethane}

The data obtained using Vernier caliper to obtain the displacement and the added mass from experiments on anti-abrasion polyurethane are shown below.

Table 3: data from experiments with ice adhesion on anti-abrasion polyurethane

\begin{tabular}{|c|c|c|c|}
\hline \multicolumn{2}{|c|}{ Experiment: $1\left(\right.$ area $\left.\mathrm{A}=59.7 \mathrm{~cm}^{2}\right)$} & \multicolumn{2}{|c|}{ Experiment: $2\left(\right.$ area $\left.\mathrm{A}=57.4 \mathrm{~cm}^{2}\right)$} \\
\hline Mass (kg) & Displacement (mm) & Mass (kg) & Displacement (mm) \\
\hline 1.25 & 1.30 & 1.25 & 1.28 \\
\hline 2.50 & 1.46 & 2.50 & 1.84 \\
\hline 3.75 & 1.92 & 3.75 & 2.43 \\
\hline 5.00 & 2.03 & 5.00 & 2.91 \\
\hline 6.25 & 2.43 & 6.25 & 3.30 \\
\hline 7.50 & 3.01 & 7.50 & 3.85 \\
\hline \multicolumn{2}{|c|}{ Experiment: $3\left(\right.$ area $\left.\mathrm{A}=56.4 \mathrm{~cm}^{2}\right)$} & \multicolumn{2}{|c|}{ Experiment: $4\left(\right.$ area $\left.A=58.5 \mathrm{~cm}^{2}\right)$} \\
\hline 1.25 & 1.25 & 1.25 & 1.30 \\
\hline 2.50 & 1.35 & 2.50 & 2.05 \\
\hline 3.75 & 1.51 & 3.75 & 2.42 \\
\hline 5.00 & 2.31 & 5.00 & 2.93 \\
\hline 6.25 & - & 6.25 & 3.30 \\
\hline$\underline{7.50}$ & - & 7.50 & 3.83 \\
\hline \multicolumn{2}{|c|}{ Experiment: $6\left(\right.$ area $\left.\mathrm{A}=59.8 \mathrm{~cm}^{2}\right)$} & \multicolumn{2}{|c|}{ Experiment: $7\left(\right.$ area $\left.A=58.8 \mathrm{~cm}^{2}\right)$} \\
\hline 1.25 & 1.30 & 1.25 & 1.21 \\
\hline 2.50 & 1.85 & 2.50 & 1.45 \\
\hline 3.75 & 2.62 & 3.75 & 2.52 \\
\hline 5.00 & 2.93 & 5.00 & 2.73 \\
\hline 6.25 & 3.21 & 6.25 & - \\
\hline 7.50 & 3.73 & 7.50 & - \\
\hline \multicolumn{2}{|c|}{ Experiment: $8\left(\right.$ area $\left.A=59.8 \mathrm{~cm}^{2}\right)$} & \multicolumn{2}{|c|}{ Experiment: $9\left(\right.$ area $\left.\mathrm{A}=58.8 \mathrm{~cm}^{2}\right)$} \\
\hline 1.25 & 1.59 & 1.25 & 1.52 \\
\hline 2.50 & 2.90 & 2.50 & 1.60 \\
\hline 3.75 & 3.73 & 3.75 & 2.90 \\
\hline 5.00 & 3.60 & 5.00 & 3.37 \\
\hline 6.25 & 3.62 & 6.25 & 3.63 \\
\hline$\underline{7.50}$ & - & 7.50 & - \\
\hline
\end{tabular}

8.2. Analytical and Numerical Simulation Results

Analytical results were obtained through theoretical analysis of stress profile [35-39] in the longitudinal direction of the sample beam similar studies were performed by Zahra et al. [4044]. Numerical models involved icing have been studied/reviewed by Khawaja et al. and others [45-50]. In this study, numerical analysis was carried out in ANSYS® Multiphysics software. Results of normal stresses in samples with load and forces of adhesion were obtained.

\subsubsection{Anti-seepage polyurethane}

The results from the analytical study and simulations on anti-seepage polyurethane are displayed below in Table. 4 and plotted for longitudinal stress and force of adhesion in Fig. 7 and 8. 
Table 4: Normal stress between the ice layer and anti-seepage polyurethane

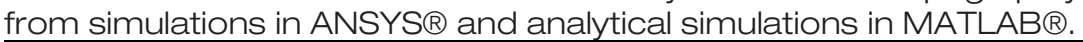

\begin{tabular}{lccc}
\hline \multirow{2}{*}{ un } & \multicolumn{2}{c}{ Normal Stress (MPa) } & Area $\left.\mathbf{( c m}^{\mathbf{2}}\right)$ \\
\cline { 2 - 3 } & ANSYS & Analytical & \\
\hline 1 & 1.42 & 1.55 & 51.4 \\
2 & 1.52 & 1.61 & 51.8 \\
3 & 1.65 & 1.76 & 52.1 \\
4 & 1.85 & 1.97 & 52.7 \\
5 & 2.19 & 2.22 & 52.9 \\
6 & 2.25 & 2.29 & 58.4 \\
7 & 2.29 & 2.32 & 55.9 \\
8 & 2.38 & 2.39 & 56.1 \\
9 & 2.48 & 2.51 & 56.9 \\
\hline
\end{tabular}

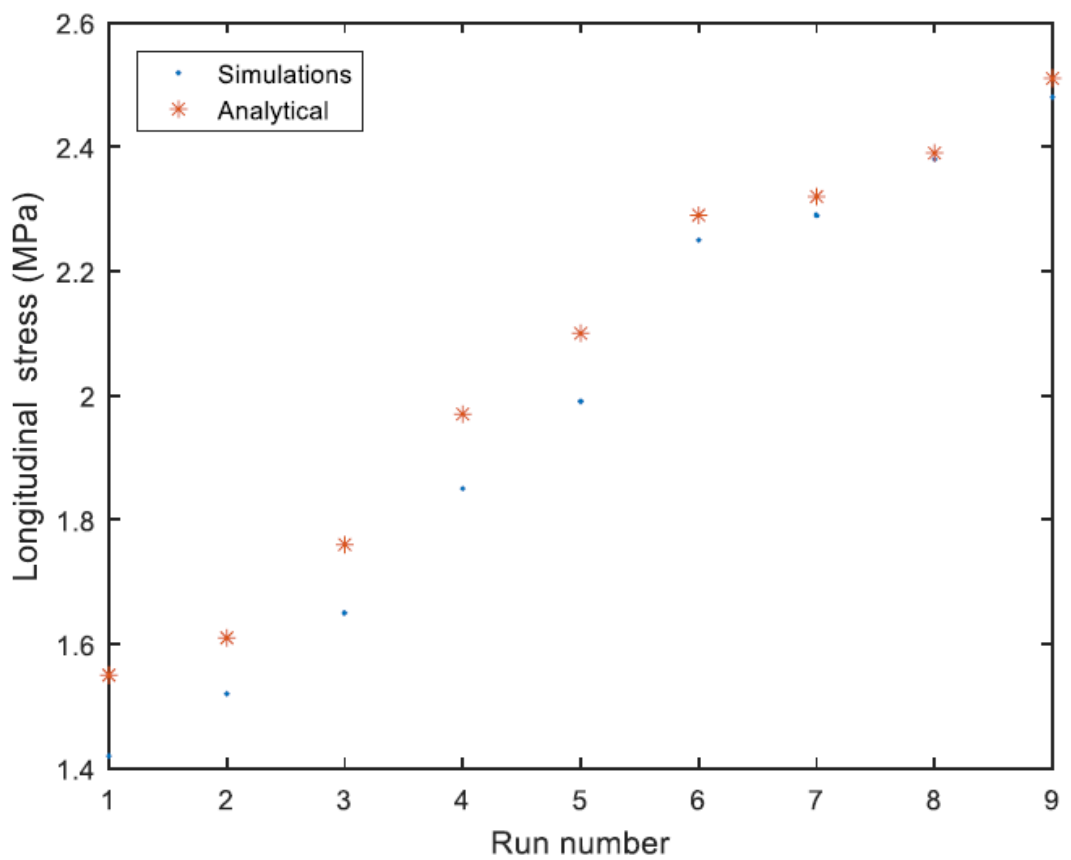

Figure 7: Longitudinal stress (MPa) between ice and anti-seepage polyurethane. 


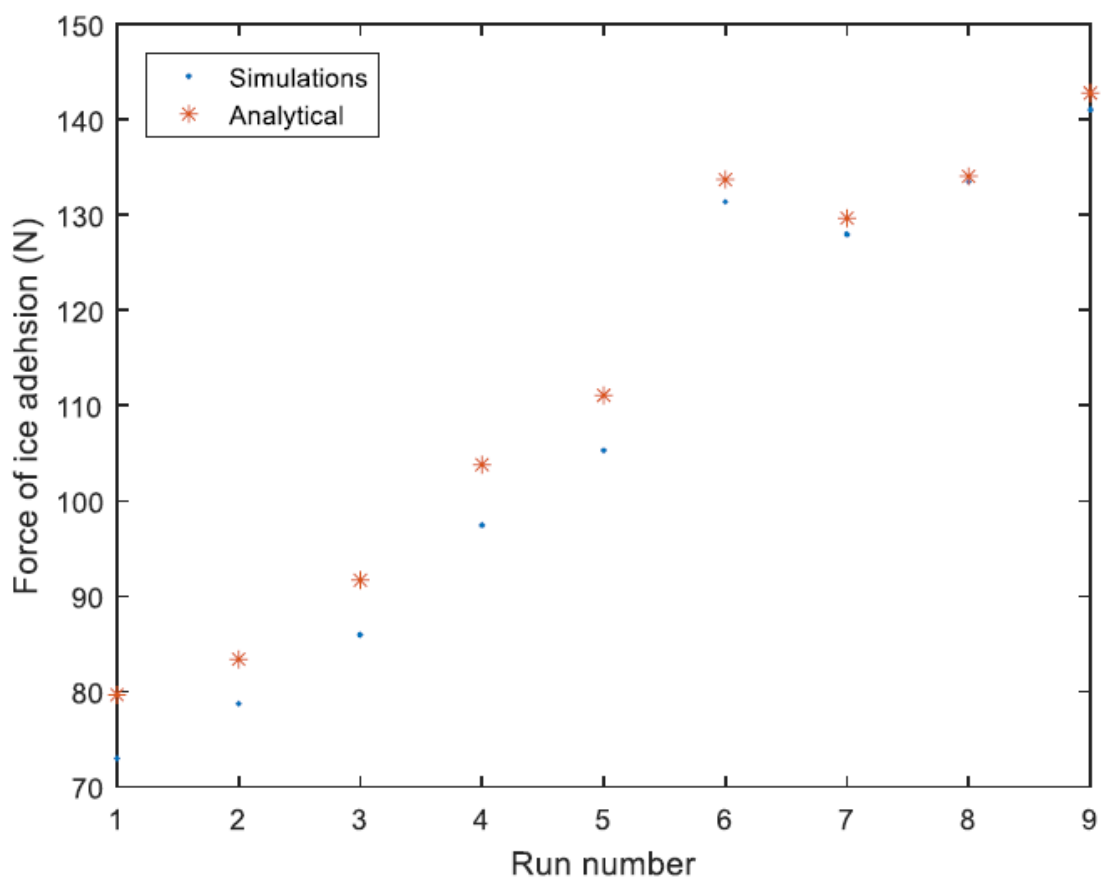

Figure 8: Ice adhesion force $(\mathrm{N})$ on anti-seepage polyurethane.

\subsubsection{Anti-abrasion Polyurethane}

The results from the analytical study and simulations on anti-abrasion polyurethane are displayed below in Table. 5 and plotted for longitudinal stress and force of adhesion in Fig. 9 and 10.

Table 5: Normal stress between the ice layer and anti-abrasion polyurethane from simulations in ANSYS $®$ and analytical calculations in MATLAB $®$.

\begin{tabular}{lccc}
\hline Run & \multicolumn{2}{c}{ Normal stress (MPa) } & \multirow{2}{*}{ Area $\left.\mathbf{( c m}^{\mathbf{2}}\right)$} \\
\cline { 2 - 3 } & ANSYS ${ }^{\circledR}$ & Analytical & \\
\hline 1 & 1.91 & 1.99 & 56.4 \\
2 & 1.99 & 2.10 & 56.9 \\
3 & 2.35 & 2.15 & 57.4 \\
4 & 2.24 & 2.23 & 58.0 \\
5 & 2.35 & 2.39 & 58.4 \\
6 & 2.35 & 2.47 & 58.9 \\
7 & 2.38 & 2.55 & 58.9 \\
8 & 2.38 & 2.66 & 59.7 \\
9 & 2.56 & 2.63 & 56.8 \\
\hline
\end{tabular}




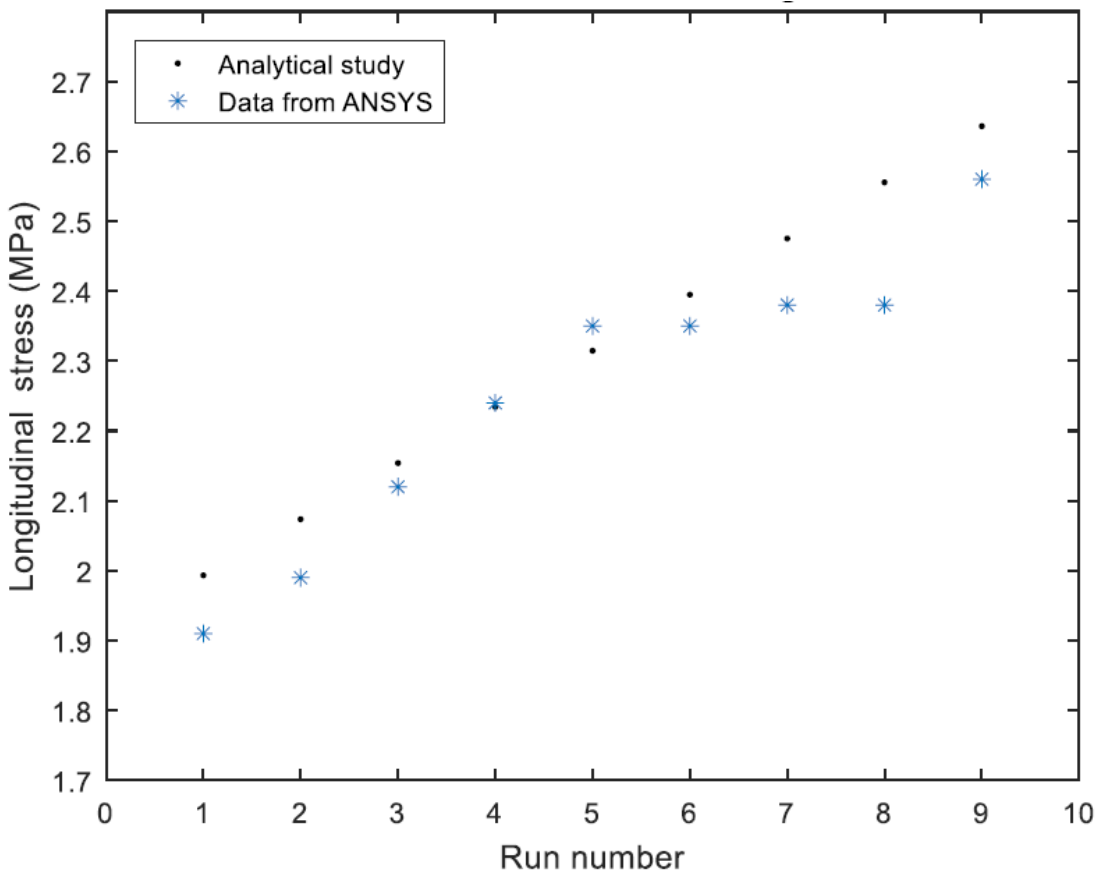

Figure 9: Longitudinal stress (MPa) between ice and anti-abrasion polyurethane.

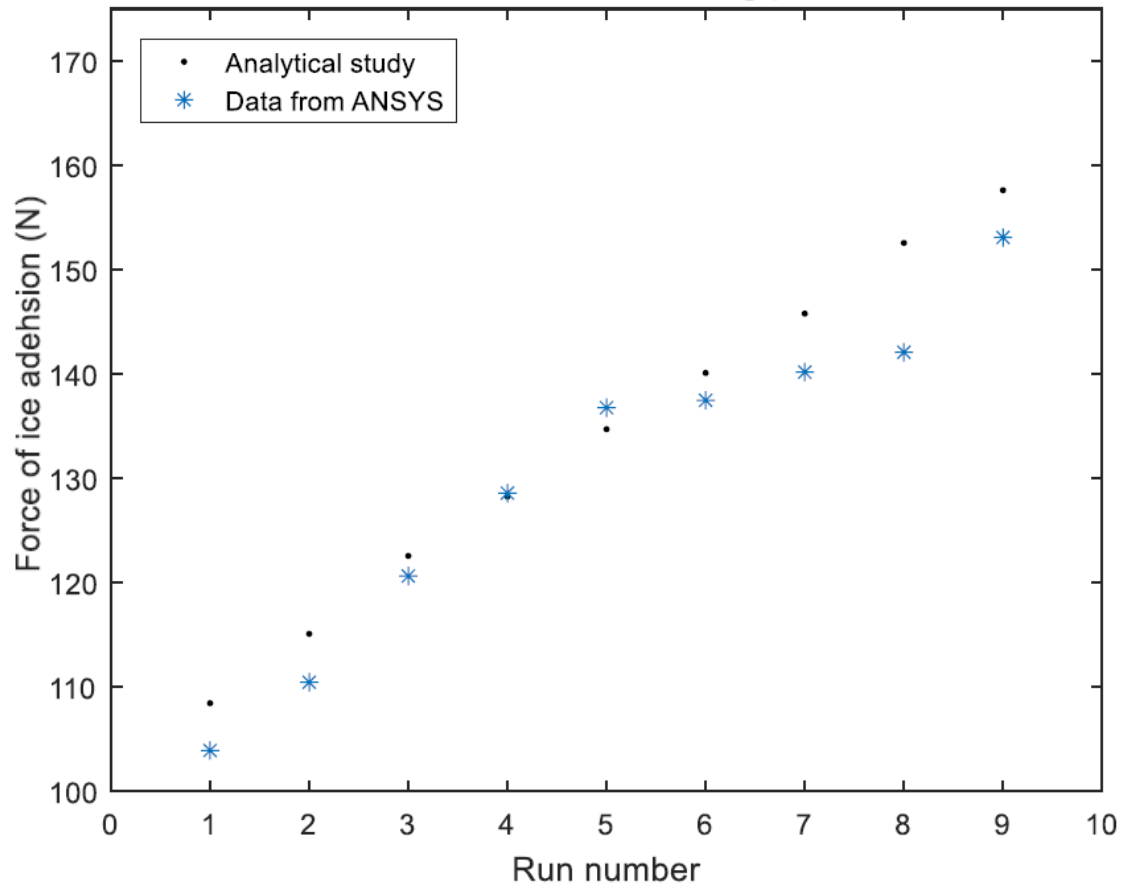

Figure 10: Ice adhesion force $(\mathrm{N})$ on anti-abrasion polyurethane. 


\section{CONCLUSIONS}

In this study, ice adhesion over the material polyurethane has been investigated using theoretical analysis, experimental and numerical approaches. The theoretical study of this work is based on the use of the Euler-Bernoulli beam theory to solve a four-point bending problem to give the correlation of displacements with load, longitudinal stress, and shear stress, and the rule of mixtures to derive common variables from two materials, such as Young's modulus, the moment of Inertia, and moment of area. Since adhesive forces can be categorized as either electrostatic, diffusive, mechanical or chemical as per the literature, there is no general correlation to work out the adhesive strength of ice over a particular surface except via experiments. Experiments with the help of theoretical analysis revealed the material properties of ice, such as longitudinal stresses. The numerical analysis provided detailed results of longitudinal stresses in the two-material beam. A good agreement among theoretical, experimental, and numerical results confirms that ice can separate from a surface even when the shear force is not enough to overcome the adhesive strength. From the results, it can be concluded that the added mass on the four-point bench, when the ice separated, varied from $5 \mathrm{~kg}$ to $7.5 \mathrm{~kg}$. However, during the test, the shear force is not enough to overcome the adhesive strength. Nonetheless, as fracture happens, the ice separates from the surface, which is associated with the crack propagation theory.

\section{ACKNOWLEDGEMENT}

The publication charges for this article have been funded by a grant from the publication fund of UiT - The Arctic University of Norway.

\section{REFERENCES}

[1] David Wahl, Philippe Giguere, “Ice Shedding and Ice Throw-Risk and Mitigation,” GE Energy, GER-4262 (04/06), Accessed: Nov. 21, 2021. [Online]. Available: http://windaction.s3.amazonaws.com/attachments/791/ge-IceShed_and_Ice_Throw.pdf

[2] Schulson, E.M. The structure and mechanical behavior of ice. JOM 51, pp. 21-27, 1999

[3] P. Hobbs, Ice physics. 2010, OUP Oxford, United Kingdom.

[4] S. Fikke, G. Ronsten, A. Heimo, S. Kunz, and M. Ostrozlik, COST 727: atmospheric icing on structures: measurements and data collection on icing: state of the art. 2006

[5] Mogens H. Foder, 2001, "ISO 12494 Atmospheric Icing of Structures And How to Use It,” onepetro.org, Accessed: Nov. 21, 2021. [Online]. Available: https://onepetro.org/ISOPEIOPEC/proceedings-abstract/ISOPE01/All-ISOPE01/ISOPEI-01-104/7913

[6] T. Rashid, H. Khawaja, and K. Edvardsen, "Determination of thermal properties of fresh water and sea water ice using multiphysics analysis,” Int. J. Multiphys., vol. 10, no. 3, pp. 277-290, 2016

[7] K. Voitkovskii, “The mechanical properties of ice,” 1962, Accessed: Nov. 21, 2021. [Online]. Available: https://apps.dtic mil/sti/citations/AD0284777

[8] F. Nimmo, L. Prockter, P. Schenk, and A. Showman, "Workshop on Europa’s Icy Shell: Past, Present, and Future: February 6-8, 2004, Houston, Texas,” 2004, Accessed: Nov. 21, 2021. [Online]. Available: https://repository.hou.usra.edu/handle/20.500.11753/1190

[9] L. W. Gold, “On the elasticity of ice plates,” Can. J. Civ. Eng., vol. 15, no. 6, pp. 10801084, 1988 
[10] M. M. Riahi, "Numerical and experimental studies of the mechanical behavior at the ice/aluminum interface,” 2007, Accessed: Nov. 21, 2021. [Online]. Available: https://constellation.uqac.ca/424/

[11] Xue, H. and Khawaja, H. (2016) "Investigation of Ice-PVC separation under Flexural Loading using FEM Analysis”, Int. J. Multiphys., vol. 10, no. 3, pp. 247-264, 2016

[12]Feng Wang, Wenwu Ding, Jianying He, Zhiliang Zhang. Phase transition enabled durable anti-icing surfaces and its DIY design, Chemical Engineering Journal, 360, pp. 243-249, 2019

[13]Z. Andleeb et al., "Multiphysics Study of Infrared Thermography (IRT) Applications,” Int. J. Multiphys., vol. 14, no. 3, pp. 249-271, 2020

[14] S. Ludvigsen, Z. Andleeb, H. Khawaja, M. Moatamedi, and B. Alzahabi, "Multiphysics Analysis of Contact Pressure Profile of Airless tires as compared to Conventional Tires,” Int. J. Multiphys., vol. 14, no. 4, pp. 399-425, 2020

[15] G. Ronsten, "Swedish experiences of wind power in cold climate-icing, ice throw and deicing,” 2004, Accessed: Nov. 21, 2021. [Online]. Available: https://www.osti.gov/etdeweb/biblio/20534713

[16]W. J. Jasinski, S. C. Noe, M. S. Selig, M. B. Bragg, "Wind turbine performance under icing conditions,” J. Sol. Energy Eng. 1998, 120(1): 60-65

[17] S. Kulinich, M. Farzaneh, "Ice adhesion on super-hydrophobic surfaces”, Applied Surface Science, 255(18), pp. 8153-8157, 2009

[18] M. Landy, A. Freiberger, "Studies of ice adhesion: I. Adhesion of ice to plastics," Journal of Colloid and Interface Science, 25(2), pp. 231-244, 1967

[19] R. Houwink, N. Bruyne, and G. Salomon, “Adhesion and adhesives,” 1965, Accessed: Nov. 21, 2021. [Online]. Available: https://www.bcin.ca/bcin/detail.app?id=118746

[20] L. H. Lee, “Adhesion of high polymers. I. Influence of diffusion, adsorption, and physical state on polymer adhesion,” J. Polym. Sci. Part A-2 Polym. Phys., vol. 5, no. 4, pp. 751760,1967

[21] K. W. Allen, “A Review of Contemporary Views of Theories of Adhesion†,” J. Adhes., vol. 21, no. 3-4, pp. 261-277, 1987

[22] S. Voiutskii, “Autohesion and adhesion of high polymers,” 1963, Accessed: Nov. 21, 2021. [Online]. Available: https://agris.fao.org/agris-search/search.do?recordID=US201300094042

[23] W. C. Wake, "Theories of adhesion and uses of adhesives: a review”, Polymer, 19(3), pp. 291-308, 1978

[24]A. Pocius and D. Dillard, Adhesion science and engineering: surfaces, chemistry and applications. 2002, Elsevier

[25] J. Bikerman, The science of adhesive joints. 2013

[26]C. Wilkes, J. Summers, C. Daniels, and M. Berard, PVC handbook. 2005

[27] S. Ramesh, T. Winie, A. K Arof, "Investigation of mechanical properties of polyvinyl chloride-polyethylene oxide (PVC-PEO) based polymer electrolytes for lithium polymer cells”, 43(5), pp. 1963-1968, 2007

[28]Beijing IWHR-KHL Co., Ltd., Accessed Dec. 12, 2021. [Online]. Available: http://www.iwhr.com/IWHREnglish/Research/Enterprises/webinfo/2016/01/1450317610212695 htm

[29] L. Deng, Y. Liu, and W. Wang, "Construction Materials and Structures of Digesters," Biogas Technol., pp. 157-199, 2020 
[30] O. A. Bauchau and J. I. Craig, “Euler-Bernoulli beam theory,” pp. 173-221, 2009

[31] H. Xue and H. Khawaja, "Investigation of Ice-PVC separation under Flexural Loading using FEM Analysis,” Int. J. Multiphys., vol. 10, no. 3, pp. 247-264, 2016

[32] C. M. Wang, "Timoshenko Beam-Bending Solutions in Terms of Euler-Bernoulli Solutions,” J. Eng. Mech., vol. 121, no. 6, pp. 763-765, 1995

[33] MATLAB \& Simulink, Accessed Dec. 12, 2021. Available from: https://matlab.mathworks.com/

[34] ANSYS|Engineering Simulation Software, Accessed Dec. 12, 2021. Available from: https://www.ansys.com/

[35] H. Khawaja, "Application of a 2-D approximation technique for solving stress analyses problem in FEM,” Int. J. Multiphys., vol. 9, no. 4, pp. 317-324, 2015

[36] H. A. Khawaja and K. Parvez, "Validation of normal and frictional contact models of spherical bodies by FEM analysis,” Int. J. Multiphys., vol. 4, no. 2, pp. 175-185, 2010

[37] H. Khawaja and M. Moatamedi, "Selection of High Performance Alloy for Gas Turbine Blade Using Multiphysics Analysis,” Int. J. Multiphys., vol. 8, no. 1, pp. 91-100, 2014

[38] M. Moatamedi, H. Khawaja. Finite Element Analysis. CRC Press (Taylor \& Francis), 2018.

[39] M. Moatamedi, T. Rahulan, H. Khawaja. Multiphysics Simulations in Automotive and Aerospace Applications. Academic Press (Elsevier), 2021.

[40]E. Stange, Z. Andleeb, H. Khawaja, and M. Moatamedi, "Multiphysics Study of Tensile Testing using Infrared thermography,” Int. J. Multiphys., vol. 13, no. 2, pp. 191-202, 2019

[41]E. Stange, Z. Andleeb, and H. Khawaja, "Qualitative visualization of the development of stresses through infrared thermography,” Vestn. MGTU, vol. 22, no. 4, pp. 503-507, 2019

[42] Z. Andleeb et al., "Multiphysics Analysis of CFRP Charpy Tests by varying Temperatures,” Int. J. Multiphys., vol. 14, no. 2, pp. 143-160, 2020

[43]Z. Andleeb et al. Strain Wave Analysis in Carbon-Fiber-Reinforced Composites subjected to Drop Weight Impact Test using ANSYS ${ }^{\circledR}$. The International Journal of Multiphysics, 15(3): 275-290, 2021

[44]Z. Andleeb et al. Thermoelastic Investigation of Carbon-Fiber-Reinforced Composites using Drop Weight Impact Test. Applied Sciences, 11(1), 2021

[45] H. Khawaja, T. Rashid, O. Eiksund, E. Brodal, K. Edvardsen. Multiphysics Simulation of Infrared Signature of an Ice Cube. The International Journal of Multiphysics, 10(3):pp. 291 - 302, 2016

[46] T. Rashid, H. Khawaja, K. Edvardsen. Review of Marine Icing and Anti-/De-Icing Systems. Journal of Marine Engineering \& Technology, 15(2): pp. 79-87, 2016

[47] T. Rashid, H. Khawaja, K. Edvardsen, Measuring Thickness of Marine Ice Using IR Thermography. Cold Regions Science and Technology, 158: pp. 221 - 229, 2018

[48] H. Xue, H. Khawaja. Review of the Phenomenon of Ice Shedding from Wind Turbine Blades. The International Journal of Multiphysics, 10(3): pp. 265 - 276. 2016

[49] Sushmit Dhar, Hassan Khawaja. Recognizing Potential of LiDAR for Comprehensive Measurement of Sea Spray Flux for Improving the Prediction of Marine Icing in Cold Conditions - A Review. Ocean Engineering, 2021, 223, 108668.

[50] Taimur Rashid, Hsin-Ling Lang, Madiha Taimur, Nicolò Chiodarelli, Michael De Volder, Kåre Edvardsen, Hassan Khawaja. Roll to Roll coating of carbon nanotube films for electro thermal heating. Cold Regions Science and Technology, 2021, 182: 103210. 